\title{
Effectiveness of an at-work Exercise Program in the Prevention and Management of Neck and Low Back Complaints in Nursery School Teachers
}

\author{
Paolo PILlASTRINI ${ }^{1 *}$, Raffaele MUGNAI ${ }^{1}$, Lucia BERTOZZI², Stefania COSTI ${ }^{3}$, \\ Stefania CURTI ${ }^{1}$, Stefano MATTIOLI ${ }^{1}$ and Francesco Saverio VIOLANTE ${ }^{1}$ \\ ${ }^{1}$ Occupational Medicine Unit, S. Orsola-Malpighi Hospital, Alma Mater Studiorum, University of Bologna, \\ Via P. Palagi 9, 40138 Bologna, Italy \\ ${ }^{2}$ School of Physiotherapy, S. Orsola-Malpighi Hospital, Alma Mater Studiorum, University of Bologna, Via \\ Massarenti 9, 40138 Bologna, Italy \\ ${ }^{3}$ Department of Oncology, Hematology and Respiratory Disease, University of Modena and Reggio Emilia, \\ Modena and Reggio Emilia, Italy
}

Received September 3, 2008 and accepted January 22, 2009

\begin{abstract}
The aim of the study was to determine the effectiveness of an extension-oriented exercise program in the prevention and management of low back/neck pain in nursery school teachers. A Cluster Randomized Controlled Trial was utilized. Seventy-one nursery school teachers working in nine school buildings were randomly divided into two groups, with each school as a unit of randomization. All the teachers in both groups received an ergonomic brochure; teachers in the experimental group also received an extension-oriented exercise program, conducted by a physical therapist. Data were collected at baseline and at a two-month follow-up. The primary outcome measure recorded was the level of disability (Roland Morris Disability Questionnaire and Oswestry Disability Index), while secondary outcome measure included the evaluation of cervical and lumbar physical discomfort (Visual Analogue Scale). At follow-up, a significant improvement was registered in the experimental group as compared to the control group for all the outcomes evaluated. In conclusion an extension-oriented exercise program may be a useful strategy to prevent low back and neck complaints and to reduce consequent LBP functional disability among nursery school teachers.
\end{abstract}

Key words: Low back pain, Neck pain, Functional disability, Nursery school teachers, Exercise program, Prevention

\section{Introduction}

Childcare in nursery schools has been shown to be associated with an elevated prevalence of neck, shoulder, arm and low back disorders ${ }^{1-4)}$. In the United States and Europe, the potential for work-related musculoskeletal disorders among nursery school teachers is largely unexplored, except for two studies performed in the US which confirm this association, demonstrating that Low Back Pain (LBP) is the most common musculoskeletal complaint among these workers ${ }^{5,6)}$. Nursery school teachers perform a

*To whom correspondence should be addressed. wide variety of tasks combining basic childcare and teaching duties, and requiring sustained mechanical load and constant trunk flexion ${ }^{5)}$. The role of these activities as risk factors for LBP is widely demonstrated ${ }^{3,7,8)}$. However, while several studies explore the management of $\mathrm{LBP}^{3,9-11)}$, only a few randomized controlled trials have been done on prevention, with conflicting results ${ }^{12,13)}$. Primary prevention refers to interventions and strategies that are implemented before a low back injury occurs ${ }^{14)}$. Secondary prevention refers to interventions and strategies that are implemented during the acute episode of low back injury, before chronic symptoms occur ${ }^{15)}$. A variety of interventions are used to prevent back and neck pain problems. In their review of back 
and neck pain preventive measures Linton and van Tulder suggest that exercises seem to be the only effective intervention and provide evidence of the lack of effectiveness of back schools and lumbar supports. Moreover, no evidence exists for ergonomic or risk factors modification due to the lack of controlled trials evaluating the effectiveness of these interventions ${ }^{16}$. Nevertheless, conflicting results have been reported on the effectiveness of an exercise program in the management of $\mathrm{LBP}^{17}$. These equivocal findings may be due both to the disparate treatment recommendations in LBP practice guidelines, and to the use of broad inclusion criteria in previous researches, which has resulted in the selection of an heterogeneous population with different stages of LBP and etiopathogenic factors ${ }^{18,19)}$. The current literature reports several extension-oriented treatment approaches involving combinations of active or passive movements to promote extension in the lumbar spine ${ }^{20,21)}$ and strengthening exercises of the primary spinal stabilizers ${ }^{22}$. The main purpose of this study is to determine the effectiveness of an at-work extension-oriented exercise program in the prevention and management of low back/neck pain and functional disability in nursery school teachers. In addition, we also sought to identify the occurrence of low back and neck complaints in this category of workers.

\section{Subjects and Methods}

\section{Study design}

This study is a Cluster Randomized Controlled Trial incorporating a combination of primary and secondary prevention strategies for limiting the occurrence and severity of low back/neck pain in nursery school teachers. The study was approved by the Medical Ethics Committee of the Area Vasta Romagna.

\section{Study population}

The study population was composed by all the 71 nursery school teachers, employed at the town hall of Forlì, that worked in nine different school buildings similar in size and furniture. As provided for by the Italian law (EmiliaRomagna Regional Law No. 1 of January 10, 2000 - art. 32, followed by the Directive of July 25, 2001), teachers had the same working schedule and the same workload in terms of teacher/children ratio depending on children age. All the teachers were female. None of them had a medical history of serious injury, spinal surgery or malignant pathology. The Experimental Group (Group E) comprised 35 teachers from five schools, while the Control Group (Group C) consisted of 36 teachers from the remaining four.

\section{Randomization and blinding}

Each school was considered as a unit of randomization in order to minimize the transfer of relevant knowledge from workers receiving the intervention to those receiving only the brochure, and thus avoid potential bias due to contamination. Schools were randomly divided into two groups, so that all the teachers of each school belonged to the same group. Concealed allocation was performed by extracting pieces of paper, each reporting a number associated with a school. Measurements were taken by two blinded health care professionals. The physical therapist who performed the intervention could not be blinded for treatment allocation. The cluster randomization procedure allowed avoidance of incidental conversations between subjects of different schools, so that the participants were blinded to the intervention received by the other group.

\section{Procedures}

The study was conducted immediately after the teachers' summer holidays. After obtaining a written informed consent from all the participants, demographic information was collected and LBP occurrence and disability were evaluated. The intervention started two days after the first evaluation, while follow-up was performed exactly two months after baseline evaluation. Teachers in Group $\mathrm{C}$ received only an ergonomic brochure, whereas teachers in Group E received the same brochure and an extension-oriented exercise program. The brochure, 52 pages long, showed the correct way to lift loads, and provided ergonomic suggestions to prevent musculoskeletal complaints, according to the Italian legislation (Law Decree 626/94 - art. 49 and further amendments and integrations, Ministerial Decree of October 2nd 2000). The extension-oriented exercise program was conducted by a physical therapist.

\section{Intervention}

The exercise program was composed of six graded sessions, two per week, with a two-day interval between sessions, for three consecutive weeks. Sessions, each of one hour length, were conducted after the working hours in a wide room of the nursery school, gathering together all the teachers from each school. The exercises were selected in order to reinforce lumbar extension ${ }^{20,21)}$ and to strengthen the primary stabilizers of the spine (transversus abdominis, oblique abdominal, multifidus, quadratus lumborum and erector spinae muscles) ${ }^{22}$. The physical therapist prescribed prone lumbar extension, upright lumbar extension, quadruped lumbar extension, quadruped hip extension, bridging, abdominal isometric contraction, upright abdominal isometric contraction with the trunk leaning against the wall (Appendix 1). The teachers were instructed to repeat their exercises during the working hours in the following months, but without the guidance and supervision of the physical therapist. Moreover the physical therapist provided explanations to the teachers about the possible ethiopatogenetic factors of LPB and instructions or advice 
to guide subjects through a process of desensitization of fears and concerns and to reduce pain attitudes and beliefs.

\section{Outcome measures}

The primary outcome measure used in this trial was the perceived level of disability as a result of LBP, assessed by the following self-administered evaluation scales: the Roland Morris Disability Questionnaire (RMDQ) and the Oswestry Disability Index (ODI). The RMDQ is validated in Italian ${ }^{23)}$, and comprises 24 items in which greater levels of disability are reflected by higher numbers on a 24-point scale ${ }^{24)}$. The RMDQ has been shown to yield reliable measurements, which are valid for inferring the level of disability, and to be sensitive to change over time for groups of patients with $\mathrm{LBP}^{25,26)}$. The ODI, which was used in the Italian pre-tested version ${ }^{27)}$, is structured in 10 sections corresponding to different activities of daily living, each scored on a six-point scale $(0-5)$. Scores of 0-20\% indicate minimal disability, $20-40 \%$ moderate disability, $40-60 \%$ severe disability, $60-80 \%$ crippled, $80-100 \%$ either bed-bound or exaggerating symptoms ${ }^{28,29)}$. Secondary outcome measure included the evaluation of cervical and lumbar physical discomfort. Participants were asked to rate the pain intensity of these two sites as pre-determined sites of pain on a Visual Analogue Scale (VAS). Was used a $10 \mathrm{~cm}$ VAS with 0 corresponding to no pain, and 10 to the worst possible pain. The VAS has been proved to be reliable and satisfactory in the measurement of pain $^{30)}$. Subjects were considered symptomatic with VAS scores $\geq 1$; at follow-up, participants were considered (changed), improved or worsened, if their VAS scores were respectively increased or reduced by more than $5 \mathrm{~mm}$ with respect to baseline values.

\section{Data analysis}

Continuous data were expressed as mean \pm standard deviation. A skewness-kurtosis test was used to test the normal distribution of values. In cases of normal distribution, continuous variables were tested with Student's $t$ test. For non-normal distributions, two-sample tests were performed using the Wilcoxon rank-sum test. The four outcomes were analyzed by a 2-way repeated-measures ANOVA with Group (Experimental vs Control) and Time (Follow-up vs Baseline) as factors. An F-test was performed to test whether Time affected the outcome differently in the two Groups. With the aim of highlighting the effect of the intervention and to consider the possible impact of other factors on the onset of LBP and neck pain, we decided to compare the chance of improving versus worsening/unchanging (at follow-up) by developing a logistic regression model (adjusted for age, BMI, height and smoking habits) for Group E with respect to Group C. The odds ratios (OR) and $95 \%$ confidence intervals
(CI) for "being improved" at follow-up (versus worsened/unchanged) were calculated as measures of association. Stata 9.0 SE software (Stata Corporation, Texas, TX) was used for all analyses, with significance set at $p<0.05$.

\section{Results}

All the 71 nursery school teachers included in the study completed the six sessions of the exercise program and were re-evaluated at the two-month follow-up. The high compliance may be explained by the small sample size, the short follow-up period and the fact that the intervention was conducted in the occupational setting after working hours. At baseline, the demographic characteristics of the two groups were very similar for age, height, weight, BMI and work experience (Table 1). When comparing the four outcome measures before intervention, no statistical differences were found (RMDQ $p=0.7895$, ODI $p=0.5680$, and symptoms at low back $p=0.6673$ ) except for neck pain $(p=0.0246)$ (Table 2). At follow-up, a great improvement was obtained in the experimental group for the primary outcome measure (Table 2). In the analysis between groups, the decrease in RMDQ and ODI scores observed in the experimental group was statistically significant with respect to the score difference before and after intervention in the control group. A statistically significant improvement was also observed in secondary outcome measures. After the intervention, the intensity of lowback/neck symptoms was significantly reduced in the experimental group as compared to the control group (Table 2). Table 3 shows the proportion of participants, whose low back and neck VAS scores at follow-up were respectively unchanged, improved or worsened with respect to baseline. Subjects with improved low back VAS score were $62.9 \%$ in Group E compared to $13.9 \%$ in Group C, whereas for neck score improved subjects were $37.2 \%$ in Group E compared to 5.6\% in Group C. According to the same trend, the proportion of participants with worsened VAS scores was higher in Group C both for low back and neck disorders. The logistic regression model (adjusted for age, BMI, height and smoking habits) showed an increased chance of improving versus worsening/unchang-

Table 1. Characteristics of the two groups

\begin{tabular}{lccc}
\hline & $\begin{array}{c}\text { Group C } \\
\mathrm{N}=36 \\
\text { mean } \pm \mathrm{SD}\end{array}$ & $\begin{array}{c}\text { Group E } \\
\mathrm{N}=35 \\
\text { mean } \pm \mathrm{SD}\end{array}$ & $p$ \\
\hline Age, yr & $43.5 \pm 7.9$ & $44.7 \pm 7.4$ & $0.498^{\mathrm{a}}$ \\
Height, m & $1.63 \pm 0.06$ & $1.63 \pm 0.05$ & $0.828^{\mathrm{a}}$ \\
Weight, kg & $60.3 \pm 11.8$ & $60.7 \pm 10.1$ & $0.721^{\mathrm{b}}$ \\
BMI, $\mathrm{kg} / \mathrm{m}^{2}$ & $22.8 \pm 5.2$ & $22.9 \pm 3.4$ & $0.585^{\mathrm{b}}$ \\
Work experience, month & $222.8 \pm 116.0$ & $251.7 \pm 125.7$ & $0.311^{\mathrm{b}}$ \\
\hline
\end{tabular}

${ }^{\mathrm{a}} t$-test, ${ }^{\mathrm{b}}$ Wilcoxon rank-sum test. 
Table 2. Comparison between the two groups before and after intervention for the four outcomes evaluated

\begin{tabular}{|c|c|c|c|c|c|c|c|}
\hline & \multicolumn{2}{|c|}{ Baseline } & \multicolumn{2}{|c|}{ Follow-up } & \multicolumn{2}{|c|}{ Score difference baseline-follow-up } & \multirow[b]{2}{*}{$p^{\mathrm{a}}$} \\
\hline & $\begin{array}{c}\text { Group C } \\
\mathrm{N}=36 \\
\text { mean } \pm \mathrm{SD}\end{array}$ & $\begin{array}{c}\text { Group E } \\
\mathrm{N}=35 \\
\text { mean } \pm \mathrm{SD}\end{array}$ & $\begin{array}{c}\text { Group C } \\
\mathrm{N}=36 \\
\text { mean } \pm \mathrm{SD}\end{array}$ & $\begin{array}{c}\text { Group E } \\
\mathrm{N}=35 \\
\text { mean } \pm \mathrm{SD}\end{array}$ & $\begin{array}{c}\text { Group C } \\
\mathrm{N}=36 \\
\text { mean } \pm \mathrm{SD}\end{array}$ & $\begin{array}{c}\text { Group E } \\
\mathrm{N}=35 \\
\text { mean } \pm \mathrm{SD}\end{array}$ & \\
\hline RMDQ [0-24] ${ }^{\mathrm{b}}$ & $3.9 \pm 3.9$ & $3.9 \pm 3.4$ & $3.8 \pm 3.7$ & $1.9 \pm 2.3$ & $0.11 \pm 0.85$ & $1.97 \pm 2.41$ & 0.0000 \\
\hline ODI $[\%]^{\mathrm{c}}$ & $8.3 \pm 7.9$ & $6.4 \pm 5.4$ & $8.3 \pm 8.0$ & $3.8 \pm 4.1$ & $-0.03 \pm 1.56$ & $2.57 \pm 2.94$ & 0.0000 \\
\hline LBP $[0-10]^{\mathrm{d}}$ & $5.4 \pm 3.0$ & $5.4 \pm 2.8$ & $5.4 \pm 3.1$ & $3.7 \pm 2.6$ & $-0.03 \pm 0.81$ & $1.66 \pm 2.06$ & 0.0000 \\
\hline Neck pain $[0-10]$ & $1.9 \pm 3.0$ & $3.8 \pm 3.4$ & $2.3 \pm 3.1$ & $2.9 \pm 3.1$ & $-0.33 \pm 1.37$ & $0.86 \pm 1.96$ & 0.0041 \\
\hline
\end{tabular}

${ }^{\mathrm{a}}$ F-test, ${ }^{\mathrm{b}}$ Roland Morris Disability Questionnaire, ${ }^{\mathrm{c}}$ Oswestry Disability Index, ${ }^{\mathrm{d}}$ Low Back Pain.

Table 3. Proportion of participants unchanged, improved and worsened at follow-up regarding pain intensity (VAS score) for low back and neck

\begin{tabular}{lcclcc}
\hline & \multicolumn{2}{c}{ LBP } & & \multicolumn{2}{c}{ Neck Pain } \\
\cline { 1 - 3 } \cline { 5 - 6 } \cline { 5 - 6 } & Group C & Group E & & Group C & Group E \\
& $\%(\mathrm{n} / \mathrm{N})$ & $\%(\mathrm{n} / \mathrm{N})$ & & $\%(\mathrm{n} / \mathrm{N})$ & $\%(\mathrm{n} / \mathrm{N})$ \\
\hline Improved & $13.9(5 / 36)$ & $62.9(22 / 35)$ & & $5.6(2 / 36)$ & $37.2(13 / 35)$ \\
Unchanged & $66.7(24 / 36)$ & $28.6(10 / 35)$ & & $83.3(30 / 36)$ & $57.2(20 / 35)$ \\
Worsened & $19.4(7 / 36)$ & $8.5(3 / 35)$ & & $11.1(4 / 36)$ & $5.6(2 / 35)$ \\
\hline
\end{tabular}

ing (at the follow-up) for Group E with respect to Group C (LBP: OR 11.8, 95\%CI 3.5-39.9; Neck Pain: OR 11.3, 95\%CI 2.1-60.2). The baseline prevalence of LBP among all the teachers of both groups was $85.91 \%$ (subjects were considered symptomatic with VAS scores $\geq 1$ ), with a mean VAS score of 6.18. Regarding neck pain, the prevalence was $46.48 \%$, with a mean VAS score of 6.15 .

\section{Discussion}

Our results point to the importance of a six-session extension-oriented exercise program in the prevention and management of neck and low back complaints and in reducing consequent LBP functional disability among nursery school teachers. In Group E compared to Group C, there was a highly significant improvement for all the four outcomes evaluated. However, when considering the score difference between baseline and follow-up in Group E alone, improvement may appear to be poor as compared to that reported by other studies using the same questionnaires ${ }^{21,31}$. In fact, we obtained an improvement of 1.97 points on the RMDQ scale, and of 2.57 points on the ODI scale, while the VAS score resulted in a decrease of 1.66 points for LBP and of 0.86 for neck pain (Table 2). This is mainly due to the fact that our intervention was aimed to primary and secondary prevention in a specific work category, and the subjects recruited had no diagnosis of LBP, although most of them were symptomatic (prevalence of LBP $85.91 \%$ ). Even when symptomatic, subjects had mild disability, as documented by the low RMDQ and ODI scores at baseline. However, the improvement observed in Group E, calculated as the ratio of score difference to baseline score (Table 2), was of $50 \%$ for RMDQ score and of $40 \%$ for ODI score. This result is in line with a previous study by Jordan et al., which stated that improvement is clinically relevant if RMDQ score is reduced by at least $30 \%{ }^{32}$. The low ODI and RMDQ scores obtained at baseline are in contrast to the relatively high level of LBP (5.4 out of ten for both groups). This incongruity may be due to an overestimation of symptoms by participants on the VAS scale, whereas the ODI and RMDQ scores reflect the real level of disability, as these two questionnaires are specifically designed for the evaluation of LBP. Several reviews of the effect of exercises as a preventive measure for back and neck pain problems have appeared, generally supporting the conclusion that exercise may have a positive effect, although there is no evidence to prove this ${ }^{33,34)}$. No evidence exists about the correct exercises protocol to use in primary prevention of low back and neck pain in a specific work category. Regarding secondary prevention, the current literature provides evidence for the effectiveness both of an extension-oriented treatment approach $^{19,20,35)}$ and of strengthening exercises of the primary stabilizers of the spine ${ }^{22,36}$ in reducing LBP recurrence and disability as compared to a classical approach or to no approach. Our results agree with these studies, and suggest the need for further investigation and for preventive intervention based on different combinations of exercises, varying in intensity and duration for each specific work category. No evidence was obtained in our research regarding the effectiveness of the ergonomic brochure, as Group $\mathrm{C}$ remained substantially unchanged for all four outcomes evaluated. Among our study population, we obtained a point prevalence (baseline VAS $\geq 1$ ) of $85.91 \%$ for LBP and of $46.48 \%$ for neck pain. These values appear higher with respect to the LBP prevalence reported for other occupational categories like hospital workers (1-yr prevalence of $58.8 \%)^{37)}$ and professional cooks (1-month prevalence of $74.3 \%)^{38}$. However, these values are not directly comparable as the point prevalence underestimates the prevalence. On the other hand, when considering the one-year 
prevalence most subjects would not report a single slight or mild event as an episode of LBP or neck pain during the previous 12 months, thus underestimating, even in this case, prevalence. In conclusion we can assert that childcare in nursery schools is an occupation at high risk for the occurrence of neck and low back symptoms. The limitations of this study include the small sample size, the lack of physiologic assessment with different stages of LBP or neck pain (acute, subacute or chronic), and the relatively short follow-up period, i.e. variables that might have affected the results. In particular the exercise literature shows that the majority fails to continue the recommended exercise program after the termination of the initial program, and this fact can affect the maintenance of intervention effects over time ${ }^{39)}$. Moreover, it would have been interesting to evaluate the patient-provider interactions through the use of self-report or observational measures, as suggested by a recent report on exercise therapy for $\mathrm{LBP}^{40}$. The strengths of our study consist in the homogeneity of the population represented by a sample of the nursery school teachers working category, so that all the participants were exposed to the same etiopathogenic factors, and the good compliance of the participants in both groups with no dropouts at follow-up.

\section{Conclusions}

In conclusion this research seems to suggest that a sixsession extension-oriented exercise program, conducted in the occupational setting, can be decisive in the prevention and management of low back and neck complaints and in reducing consequent LBP functional disability among nursery school teachers, as assessed at a twomonth follow-up. No evidence was obtained regarding the effectiveness of the educational efforts of the ergonomic brochure, suggesting that the ergonomic training alone is not sufficient for the prevention and management of the trunk complaints and disability. These results must be confirmed by future studies with higher methodological standards, including a larger sample sizes, a longer-term follow-up and an initial clinical assessment for subgrouping classification. Moreover, since many factors may be relevant for the occurrence or recurrence of back/neck pain and injury, a multidimensional approach would be more effective as it would presumably cover a wider range of risk factors. In consideration of our results, a real need exists for further investigations and for preventive interventions based on multidimensional approaches with different combinations of exercises, varying in intensity, duration and typology in order to identify the correct program for the prevention and management of trunk complaints for each specific work category.

\section{References}

1) Tokunaga $R$ (1982) Work and health conditions of female workers in public nursery schools. In: Proceedings of the tenth Asian Conference on Occupational Health, Lai CS, Low WF, Lee HP, Ong CN (Eds.), 717-20, Asian Association of Occupational Health, Singapore.

2) Nagira T, Suzuki J, Oze Y, Ohara H, Aoyama H (1981) Cervicobrachial and low-back disorders among school lunch workers and nursery-school teachers in comparison with cash-register operators. J Hum Ergol 19, 117-24.

3) Kumagai S, Tabuchi $T$, Tainaka H, Miyajima $K$, Matsunaga I, Kosaka H, Andoh K, Seo A (1995) Load on the low back of teachers in nursery schools. Int Arch Occup Environ Health 68, 52-7.

4) Shimaoka M, Hiruta S, Ono Y, Nonaka H, Hjelm EW, Hagberg M (1998) A comparative study of physical work load in Japanese and Swedish nursery school teachers. Eur J Appl Physiol 77, 10-8.

5) Grant KA, Habes DJ, Tepper AL (1995) Work activities and musculoskeletal complaints among preschool workers. Appl Ergon 26, 405-10.

6) Brown MZ, Gerberich SG (1993) Disabling injuries to childcare workers in Minnesota, 1985 to 1990: an analysis of potential risk factors. J Occup Med 35, 1236-43.

7) Kelsey JL, Golden AL (1987) Occupational and workplace factors associated with low back pain. Spine: State of the Art Reviewes 2, 7-16.

8) Riihimaki H (1991) Low-back pain; its origin and risk indicators. Scand J Work Environ Health 17, 81-90.

9) Koes BW, van Tulder MW, Thomas S (2006) Diagnosis and treatment of low back pain. BMJ 332, 1430-4.

10) Assendelft WJ, Morton SC, Yu EI, Suttorp MJ, Shekelle PG (2003) Spinal manipolative therapy for low back pain: a meta-analysis of effectiveness relative to other therapies. Ann Intern Med 138, 871-81.

11) Koes BW, van Tulder MW, Ostelo R, Kim Burton A, Waddell G (2001) Clinical guidelines for the management of low back pain in primary care: an international comparison. Spine 26, 2504-13.

12) Daltroy LH, Iversen, MD, Larson MG, Lew R, Wright E, Ryan J, Zwerling C, Fossel AH, Liang MH (1997) A controlled trial of an educational program to prevent low back pain injuries. N Engl J Med 337, 322-8.

13) Lonn JH, Glomsrod B, Soukup MG, Bo K, Larsen S (1999) Active back school: prophylactic management for low back pain. A randomised, controlled, 1-year follow-up study. Spine 24, 865-71.

14) Frank JW, Kerr MS, Brooker AS, DeMaio SE, Maetzel A, Shannon HS, Sullivan TJ, Norman RW, Wells RP (1996) Disability resulting from occupational low back pain. Part I: What do we know about primary prevention? A review of the scientific evidence on prevention before disability begins. Spine 21, 2908-17.

15) Frank JW, Brooker AS, DeMaio SE, Kerr MS, Maetzel A, Shannon HS, Sullivan TJ, Norman RW, Wells RP 
(1996) Disability resulting from occupational low back pain. Part II: What do we know about secondary prevention? A review of the scientific evidence on prevention after disability begins. Spine 21, 2918-29.

16) Linton SJ, van Tulder MW (2001) Preventive interventions for back and neck pain problems. What is the evidence? Spine 26, 778-87.

17) Hayden JA, Van Tulder MW, Malmivaara A, Koes BW (2005) Exercise therapy for treatment of non-specific low back pain. Cochrane Database Syst Rev 20, CD000335.

18) Leboeuf-Yde C, Lauritsen JM, Lauritzen T (1997) Why has the search for causes of low back pain largely been nonconclusive? Spine 22, 877-81.

19) Delitto A (2005) Research in low back pain: time to stop seeking the elusive "magic bullet". Phys Ther $\mathbf{8 5}$, 206-8.

20) Machado LA, de Souza MS, Ferreira PH, Ferreira ML (2006) The McKenzie method for low back pain: a systematic review of the literature with a meta-analysis approach. Spine 31, E254-62.

21) Browder DA, Childs JD, Cleland JA, Fritz JM (2007) Effectiveness of an extension-oriented treatment approach in a subgroup of subjects with low back pain: a randomized clinical trial. Phys Ther 87, 1608-18.

22) Hayden JA, van Tulder MW, Tomlinson G (2005) Systematic review: strategies for using exercise therapy to improve outcomes in chronic low back pain. Ann Intern Med 142, 776-85.

23) Padua R, Padua L, Ceccarelli E, Romanini E, Zanoli G, Bondì R, Campi A (2002) Italian version of the Roland Disability Questionnaire, specific for low back pain: crosscultural adaptation and validation. Eur Spine J 11, 126-9.

24) Roland M, Morris R (1983) A study of the natural history of back pain, part I: development of a reliable and sensitive measure of disability in low back pain. Spine 8, 141-4.

25) Stratford PW, Binkley JM (2000) A comparison study of the Back Pain Functional Scale and Roland Morris Questionnaire. North American Orthopaedic Rehabilitation Research Network. J Rheumatol 27, 1928-36.

26) Riddle DL, Stratford PW (2002) Roland-Morris scale reliability. Phys Ther 82, 512-7.

27) http://www.orthosurg.org.uk/odi/Italian3_ODI.html. Accessed September 3, 2008.
28) Fairbank JC, Davies JB, O'Brien JP (1980) The Oswestry Low Back Pain Disability Questionnaire. Physiotherapy 66, 271-3.

29) Fairbank JC, Pynsent PB (2000) The Oswestry Disability Index. Spine 25, 2940-53.

30) Huskisson EC (1974) Measurement of pain. Lancet 2, 1127-31.

31) Goldby LJ, Moore AP, Doust J, Trew ME (2006) A randomized controlled trial investigating the efficiency of musculoskeletal physiotherapy on chronic low back disorders. Spine 31, 1083-93.

32) Jordan K, Dunn KM, Lewis M, Croft P (2006) A minimal clinically important difference was derived for the Roland-Morris Disability Questionnaire for low back pain. J Clin Epidemiol 59, 45-52.

33) Gebhardt WA (1994) Effectiveness of a training to prevent job-related back pain: a meta-analysis. $\mathrm{Br} \mathrm{J}$ Clin Psychol 33, 571-4.

34) van Poppel MNM, Koes BW, Smid T, Bouter LM (1997) A systematic review of controlled clinical trials on the prevention of back pain in industry. Occup Environ Med 54, 841-7.

35) Larsen K, Weidick F, Leboeuf-Yde C (2002) Can passive prone extension of the back prevent back problems? A randomized, controlled intervention trial of 314 military conscripts. Spine 27, 2747-52.

36) Hides JA, Jull GA, Richardson CA (2001) Long-term effects of specific stabilizing exercises for first-episode low back pain. Spine 26, E243-8.

37) Folletti I, Belardinelli V, Giovannini G, Cresta B, Fabrizi G, Tacconi C, Stopponi R, Ferrari L, Siracusa A (2005) Prevalence and determinants of low back pain in hospital workers. G Ital Med Lav Ergon 27, 359-61.

38) Nagasu M, Sakai K, Ito A, Tomita S, Temmyo Y, Ueno M, Miyagi S (2007) Prevalence and risk factors for low back pain among professional cooks working in school lunch services. BMC Public Health 24, 171.

39) Linton SJ, Hellsing AL, Bergstrom G (1996) Exercise for workers with musculoskeletal pain: does enhancing compliance decrease pain? J Occup Rehabil 6, 177-90.

40) Helmhout PH, Staal JB, Maher CG, Petersen T, Rainville J, Shaw WS (2008) Exercise Therapy and Low Back Pain. Insights and proposals to improve the design, conduct, and reporting of clinical trials. Spine 33, 1782-8.

Appendix 1. Summary of physical therapy sessions
\begin{tabular}{lcccccc}
\hline EXERCISES & Session1 & Session2 & Session3 & Session4 & Session5 & Session6 \\
\hline Prone lumbar extension & $2 \times 10$ & $2 \times 12$ & $2 \times 14$ & $3 \times 10$ & $3 \times 12$ & $3 \times 15$ \\
Upright lumbar extension & $2 \times 10$ & $2 \times 12$ & $2 \times 15$ & $2 \times 20$ & $2 \times 25$ & $2 \times 30$ \\
Quadruped lumbar extension & $2 \times 10$ & $2 \times 12$ & $2 \times 15$ & $2 \times 20$ & $2 \times 25$ & $2 \times 30$ \\
Quadruped hip extension & $2 \times 10$ & $2 \times 12$ & $2 \times 15$ & $2 \times 20$ & $2 \times 25$ & $2 \times 30$ \\
Bridging & $2 \times 10$ & $2 \times 12$ & $2 \times 15$ & $2 \times 20$ & $2 \times 25$ & $2 \times 30$ \\
Abdominal isometric contraction & $5 \times 10 \mathrm{~s}$ & $10 \times 10 \mathrm{~s}$ & $15 \times 10 \mathrm{~s}$ & $20 \times 10 \mathrm{~s}$ & $20 \times 15 \mathrm{~s}$ & $20 \times 20 \mathrm{~s}$ \\
Upright abdominal isometric contraction & $5 \times 10 \mathrm{~s}$ & $10 \times 10 \mathrm{~s}$ & $15 \times 10 \mathrm{~s}$ & $20 \times 10 \mathrm{~s}$ & $20 \times 15 \mathrm{~s}$ & $20 \times 20 \mathrm{~s}$ \\
with trunk leaning against the wall & & & & & &
\end{tabular}

